\title{
CARMINA LATINA
}

\section{Michael von Albrecht}

Universität Heidelberg, (Professor emeritus),

Voßstraße 2, Geb. 37, 69115, Heidelberg, Deutschland; albrecht@urz.uni-heidelberg.de

\section{Ad Scientiarum Academiam Rossicam A Petro Magno Conditam}

Quam Petrus ingens condiderat, vocas

Me, Russiae vox sancta academicae?

Tantone respondere honori Lingua valet titubans vel audet?

Europa quidquid docti habuit, locum Audens in unum cogere cogitat

Solemque terras Imperator Spectat ad occiduum patentes.

Artem ex Batavis discere nauticam Iuvit; mathesin mox docet Eulerus

Helvetius; Germane, Naucki, Fragmina tu tragica edidisti.

Boethlingkii sunt lexica Sanscrita Permagna apud vos Petropoli edita:

Perstant adhuc ac permanebunt, Nam melius nihil est repertum.

Sed disciplinas quis totidem simul Complectitur? Quis historiam tenet

Rerumque naturam ac poesin?

$\mathrm{Tu}$, Mikhail Lomonossov, unus.

Quam magna facta es ex humili cito!

Quae cum fuisses ultima tempore,

Es facta mox virtute prima,

Sic, academica laurus, aucta es.

Iam docta crevit Russia fortior.

Nativa quot sunt nomina grandia!

Et quot parum notos habetis,

Nomina quorum hodie resurgunt!

(C) St. Petersburg State University, 2016 
Ut luce clarus Sol propria nitet,

Non indigetis amplius advenis.

Tanto magis commotus intro

Tot patribus venerata templa.

Avus mathesin Petropoli colit,

Mosquae, Taneev, instituis patrem,

Cui Musa Russici ${ }^{1}$ remansit

Plena saporis in omne tempus.

Idem, Thaddaei discipulus memor,

Linguam Latinam tradere filio

Curavit, et Graecae poesis

Incutit immodicos amores.

Sed voce viva dum puero legit

Musasque mater Teutonicas refert,

Et Russicam linguam ac poesin

Vox aviae reserat nepoti.

Proinde siquid est, quod ego afferam,

Sciatis unde haec omnia fluxerint.

Sunt vestra de vestris. Fruenda

Omnia grato animo remitto.

\section{De librorum non scriptorum bibliotheca in Utopia sita}

Librorum numquam natorum bibliotheca, Amice lector, te vocat.

Commoda quanta tibi dentur, nunc percipe, cuncta

Servaque corde condita!

Ecce aditûs nemo custodit, portaque nostra est

Noctu diuque pervia,

Tempore tu quovis potes huc intrare, neque ullas

Habemus umquam ferias.

Ante fores ex te non quaerit Cerberus ullus,

Professor an doctor sies.

Tangere nec libros quisquam vetat, omne volumen

Evolvere aude! Nam licet.

\footnotetext{
${ }^{1}$ Varia lectio: nativi.
} 
En faciles lectu cuncti stant ordine libri,

Potes carere interprete.

Nempe albae sine labe, quibus nil clarius, omnes

Vacant liturâ paginae.

Cunctis candor adest foliis, et littera nulla

Infestat hanc albedinem.

Quid quod ab his libris absunt mendacia cuncta,

Patetque nuda veritas?

Invenies illic, sapiens quaecumque tacere

Non eloquenda maluit:

Socratis hic non scripta, Plato, tua mystica dicta,

Iesuque verba authentica,

Hic etiam invenies inenarrabile quidquid

Sanctis revelat ecstasis,

Dulcia nec deerunt: quidquid percepit amantum

Mens sevocata a corpore.

Non opus est instrumentis aut retibus ullis:

Tu computatra proice.

Huc accede: aperit gratis sapientia fontes.

Hos tolle libros et lege!

\section{Ad Almam Matrem Tubingensem}

Somnio? Num vere est iam sexagesimus annus,

Sedem ex quo tetigi, docta Tubinga, tuam?

Anne iterum „Via Guilelmi“ calcanda? Vocatur

Illa „academicum“ adhuc nomine „curriculum“?

Praeterii magnam tiro tunc bibliothecam,

In qua Manfredus ${ }^{3}$ lexica magna facit,

Quo nemo est Arabum sermonis gnarior. Annos

Tot, qui sufficiant perficere illud opus,

Optarim tibi! Tu monstras, carissime, quae sit

Soli doctrinae dedita vita sacrae.

Transeo praeterea „Centralem“ tiro „Tabernam“,

Caffeam ubi potans dulcia liba capis,

Indica dum vertis, Glasenappi, carmina, docte!

Lexicon ut desit, reddere cuncta vales.

Omnia enim tecum portas, linguae ipse peritus.

Salve, vir sapiens atque facete, mihi!

${ }^{2}$ Ita eam viam (semper repletam discipulis) appellabat Otto Weinreich.

${ }^{3}$ Manfred Ullmann. 
Aulam pervenio ad Veterem. Mirorque notoque

Librorum esse satis, aëris esse parum.

Ernestum $^{4}$ invenio verum sanctumque magistrum,

Qui me in templa vocat, Musa Latina, tua.

Vespere discipulos proprias Volfangus ${ }^{5}$ in aedes

Invitat. Veniunt. Iam legiturque Plato.

Non mera verba tamen, sed res spectare iuvabat.

Rixabamur enim, verane dicta forent.

Adrides nobis, maior Volfange, superne,

Goethe, - replet muros editionis onus.

Tunc, Conrade 6 , aderas, o humanissime, dulcis,

Cui vitae spatium perbreve fata dabant.

$\mathrm{Te}$, Joachim ${ }^{7}$, posthac vidi coluique. Platonis

Longa data est sophiae totaque vita tua.

Fortunata Tubinga, Syracosiique ${ }^{8}$ beati

Egregios cives vos habuere duos!

Maior nunc ambos Res Publica laudibus ornat,

Ipse Plato campos ducit in Elysios.

Haud frustra sapiens quondam mihi dixerat Otto':

„Non vino dives sum, sed amicitia“.

Quos socios mihi fers! Quos discipulosque, Tubinga!

Quot memorare velim nomina cara mihi!

Unum pro cunctis liceat laudare. Valahfrid ${ }^{10}$,

Curriculo exacto iam tibi trado facem.

For citation: Albrecht M. von. Carmina Latina. Philologia Classica 2016, 11(1), 163-166.

DOI: $10.21638 / 11701 /$ spbu20.2016.114

Received: 10.02.2016

Final version received: 19.05.2016

\footnotetext{
${ }^{4}$ Ernst Zinn.

Wolfgang Schadewaldt.

Konrad Gaiser.

Hans J. Krämer.

Utrique philosopho a Syracusanis ius civium honoris causa datum est.

Otto Weinreich.

${ }^{10}$ Wilfried Stroh.
} 